\title{
The Necessary Way for the Development of China's Rural Areas in the New Era-Rural Revitalization Strategy
}

\author{
Han Wang, Yi Zhuo \\ Business School of Finance Management, Hohai University, Nanjing, China \\ Email: 1246872320@qq.com, zy99619@163.com
}

How to cite this paper: Wang, $H$. and Zhuo, Y. (2018) The Necessary Way for the Development of China's Rural Areas in the New Era-Rural Revitalization Strategy. Open Journal of Social Sciences, 6, 97-106. https://doi.org/10.4236/jss.2018.66010

Received: May 29, 2018

Accepted: June 8, 2018

Published: June 11, 2018

Copyright (c) 2018 by authors and Scientific Research Publishing Inc. This work is licensed under the Creative Commons Attribution International License (CC BY 4.0).

http://creativecommons.org/licenses/by/4.0/

\begin{abstract}
The Nineteenth National Congress of the Communist Party put forward the strategy of "rejuvenation of villages". In the "two sessions", the strategy was again emphasized that the implementation of the strategy for the revitalization of rural areas relates to whether or not the rural economy can recover from decline to full development. It is of great significance to build the "Chinese dream". Therefore, it explores the ways to achieve full rejuvenation in rural areas and analyzes possible problems and solutions in the implementation of strategies.
\end{abstract}

\section{Keywords}

Rural Revitalization Strategy, Three Rural Issues, Urban-Rural

Integration, Approach, Significance, Rural Construction, Resource Flow

\section{Introduction}

At the 13th National People's Congress, General Secretary Xi Jinping put forward the idea of "implementing the strategy of village rejuvenation is a big article, to make overall planning and scientific progress", and once again stressed that the "village rejuvenation" is a major strategy which has fundamental impact on national livelihood. The meaning of rural revitalization is to "maintain the priority of rural development, establish a sound urban-rural integration development system and policy system, and accelerate the modernization of rural areas in accordance with the general requirements of industrial prosperity, ecological livability, rural civilization, effective governance, and affluent life". As early as last year's 19th National Congress of the Communist Party of China, General Secretary Xi proposed that the implementation of the strategy of "reju- 
venating the countryside" is a major historic task for success in building a well-to-do society and an all-round construction of a modern socialist country. It is important to do a good job of "three rural issues" in this new era [1]. With the advancement of social modernization and urbanization, the state pays more and more attention to the "three rural issues" and places the development of rural economy first. Therefore, it is imperative for the "village revitalization" to take place.

The "three rural issues" refer to agriculture, rural areas and farmers which is not only an economic issue, but also a political issue and a social issue. In recent years, a large number of experts and scholars have conducted relevant research and intense discussion. Zhao Zhongsheng proceeded from the peasants' rights and interests, and took the "capacity-dominated resource theory" as the analytical framework. He put forward that the peasants' rights and abilities are the core of the "three rural issues" problem. Lin Yifu believes that the core issue of the "three rural issues" is the issue of farmers. The key to solve the "three rural issues" is to maintain a steady development of agriculture, increase the income of peasants, and reduce the gap between urban and rural areas and between regions. Xue Menglin believes that from an internal perspective, the issue of "three rural issues" is fundamentally a question of land and peasants. From the outside, we need to start with the relationship between the state and the "three rural issues", the relationship between urban and rural areas, and the relationship between agriculture and the secondary and tertiary industries. Meantime, the agricultural issue is the core of the "three rural issues" issue. The peasant issue is a difficult issue. The rural issue is the strategic support point for solving the "three rural issues" issue.

All sectors of society have also expressed their opinions in order to solve the "three rural issues". Han Jun pointed out that the current solution to the "three rural issues" has come to the crucial stage. We need to give farmers more land rights, such as land use rights, income rights, and free transfer rights. It is necessary to accelerate the establishment of public service system, the establishment of an impeccable rural financial system, and support the free movement of farmers to the cities. Li Guoxiang believes that promoting industrial integration requires adjusting the agricultural structure, changing the direction of agricultural development, and accelerating the structural reform of the agricultural supply side. With the continuous expansion of e-commerce, the new industrial structure of "Internet plus three rural issues" has emerged. He Xuefeng and Yin $\mathrm{Zi}$ believe that the modernization of agriculture cannot ignore the existence of small-scale peasant economy, and should respect the laws of agricultural production on the basis of the small-scale peasant economy, gradually realizing agricultural modernization. Zhang Yibo believes that accelerating agricultural modernization must promote the integration of rural primary, secondary and tertiary industries.

All in all, the strategy of "Rural Revitalization" is a major strategy for solving the "three rural issues" and a necessary way for rural development in the new era 
in China. For this reason, this paper focuses on the feasibility and problems need to be avoided in the implementation of the "Rural Revitalization" strategy in China. It aims to reflect the Chinese government's emphasis on the development of rural areas and its determination to promote equal development between rural and urban areas.

\section{The Significance of "Rural Revitalization"}

\subsection{The Gap between Urban and Rural Areas Is Too Large and Rural Decline Is Serious}

After 40 years of reform and opening up, socialism with Chinese characteristics has entered a new era. On the one hand, economic and social development has made great progress, laying a solid foundation for the Chinese dream of realizing the great rejuvenation of the Chinese nation in the middle of this century. On the other hand, the main social contradictions have been transformed into the contradiction between the people's growing good living needs and unbalanced development [1]. The biggest imbalance is the unbalanced development of urban and rural areas, and the biggest deficiency is inadequate rural development.

Through Figure 1, we can see that China's per capita income and consumption levels are increasing year by year, but urban residents' income levels and consumption levels are significantly higher than rural residents, and the gap is widening year by year. If this gap is not controlled and narrowed, it will cause social order to be threatened and economic development hindered.

In our country's continuous process of industrialization and urbanization, the dual structure of urban and rural areas in China has become more prominent, because in this process, a large number of young and middle-aged labor from rural areas have flooded into towns and cities, especially those with great attraction and powerful cities such as Beijing, Shanghai, Guangzhou, Shenzhen, etc. [2]. These people live and work in the cities and towns, increasing their own family income, and also enjoyed the benefits brought about by the modernization of society. They also made a contribution to the development of the urban economy. In contrast, in rural areas, due to the one-way outflow of labor and other production factors, the local economy and development have become even more backward, resulting in incomplete infrastructure construction in rural areas. As a result, more and more "empty nest" and "hollow villages" and "Left-behind children" have emerged. What's more, the trend of aging population is also becoming more and more serious [3].

It can be seen from Figure 2 that during the ten years from 2007 to 2016, the urban population continued to grow, but the rural population continued to decrease, and the trend is obvious. This phenomenon led to excessive "congestion" of cities and serious rural decay [4].

The decline of rural areas is not only the loss of human resources, but the lag in industrial development. From the perspective of the rural industrial structure, the main problem of the primary industry in China is that the production 


\section{Urban and rural income and consumption expenditure comparison (unit: yuan)}

40000
35000
30000
25000
20000
15000
10000
5000
0

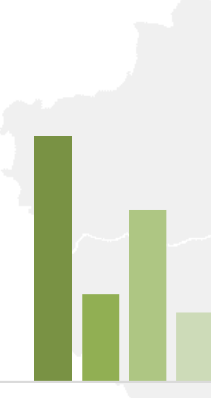

2013

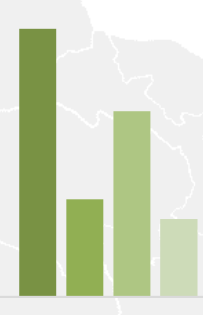

2014

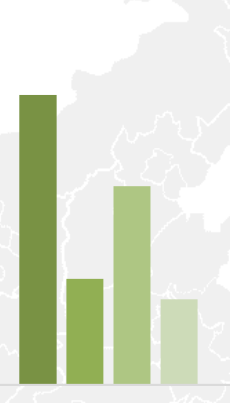

2015

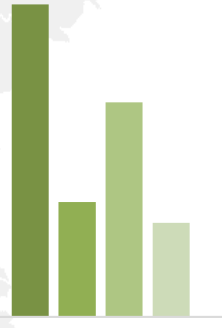

2016

- Urban residents' disposable income

nural residents' disposable income

- Urban per capita consumption expenditure

Per capita consumption expenditure of rural residents

Figure 1. Comparison of urban and rural income and consumption (Source: National Bureau of Statistics of China).

\section{Urban and Rural Population Change (Unit: Ten Thousand)}

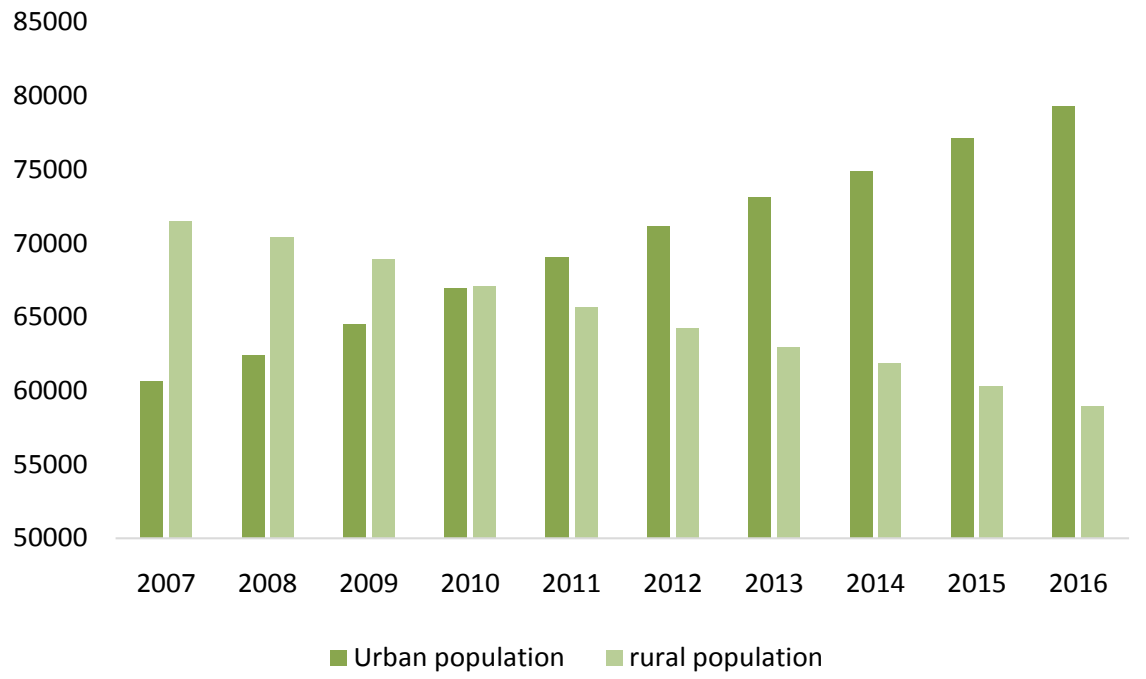

Figure 2. Trend of population change in urban and rural areas in China (Source: National Bureau of Statistics of China).

efficiency is not high, especially in the poor areas where still use traditional backward production methods. The secondary industry in rural areas falls behind in the production process. The development of the tertiary industry in rural areas lags behind. In general, the modern rural industrial system has not yet formed.

Although China has been a large agricultural country since ancient times, it is 
not a strong country in agriculture, and it still belongs to developed countries in the international arena. In the world rankings, China's comprehensive agricultural modernization ranking is only ranked 65th and does not match China's overall strength. Family-based small-scale agricultural business models constrain the investment in modern elements of agriculture. As a result, agricultural production capacity is weak and low efficiency, and the structural contradictions of agricultural products are prominent. This results in the lack of international competitiveness of agricultural products and a large difference from the international level. Especially in recent years, due to the low comprehensive efficiency of China's agriculture and the stable production of major agricultural products in overseas countries, the prices of domestic bulk agricultural products are higher than those in the international market, making China's agriculture under great pressure.

The problems of education in rural areas are also very acute. Especially in poor areas, compulsory education is not universal, and a large number of children cannot enjoy normal basic education. What's more, most of these children are "left-behind children". They not only cannot accept knowledge, but also have serious psychological obstacles. In addition, medical and infrastructure construction in rural areas lags behind. With the ecological environment has been destroyed and traditional culture has gradually disappeared, the whole countryside has been declining.

China is a traditional agricultural country. The development of rural areas is a fundamental issue that affects the livelihood of our people. The development of the city depends on the continuous supply of diverse and versatile products from the rural areas and a good ecological environment in rural areas. Accelerating the "urban-rural integration" process and narrowing the gap between urban and rural areas can ensure the stable development of society.

\subsection{Rural Revitalization Is Beneficial to "Chinese Dream"}

The great rejuvenation of the Chinese nation is the dream of every Chinese. The great rejuvenation of the Chinese nation is not only to rejuvenate the city, but also to bring the countryside on the way to recovery. The farmers' dream of living a well-to-do life is also an indispensable component of the "Chinese dream". Since the reform and opening up, especially the idea of "Chinese Dream" was putting forward, the Party Central Committee headed by General Secretary Xi has increased its support for rural areas, visiting major poverty-stricken mountain areas to understand the public, and implemented policies such as "precise poverty alleviation". Millions of farmers are out of poverty each year. However, there are still many rural areas that are very poor. It will take a long time to change it if we just rely on the support of the government and the developed regions. Implementing the strategy of "rejuvenating the country" can fundamentally solve the problem of poverty, promoting the overall development of the rural economy, providing more opportunities for rural areas, and let farmers rely on their own efforts to live a well-off and even prosperous life is the fundamental 
way. In addition, after implementing the "village rejuvenation" strategy, with policy support and the deepening of "urban-rural integration", more physical, financial, and human resources will flow to rural areas, and rural medical and educational infrastructure will be provided. As a result, some migrant workers will return home. This will not only bring new vitality to the rural areas, but also relieve urban pressure, contributing to the realization of the "Chinese Dream".

\section{Approach to Achieve "Village Rejuvenation"}

\subsection{Strengthen Cultural Education for Farmers and Increase the Construction of Rural Talents}

To achieve "village rejuvenation", we must strengthen the construction of rural cultural education at first so that the level of farmers' own knowledge quality has been improved. At present, there are still many remote areas in China that do not have universal access to compulsory education. Many children in rural areas have no access to education, and their survival skills are single and backward, and they cannot keep up with modern life. The government should increase investment in rural cultural education, rebuild rural schools that have been blindly removed, and ensure that the most basic compulsory education for rural children can be completed. Government should carry out projects for peasant college students, educating farmers on new technologies and help them to take root in rural areas, developing agriculture. Cultivate rural professional and technical talents in colleges and vocational colleges and make this part of the population contribute to the construction of the new rural area.

To achieve "village rejuvenation", we must break the bottleneck of talent [5]. There are two types of talents here. The first category is to have excellent grass-roots cadres. They are in close contact with the grass-roots people, and they are most familiar with the needs and difficulties of peasants. The 19th Congress The report proposes that we must cultivate a team of "three rural" workers who understand agriculture, love rural areas and love farmers. With these cadres who love the people, and have a high sense of Party spirit, the interests of the peasants can be guaranteed. In addition, these cadres should be provided with more learning opportunities to improve their own cultural quality standards, and better help the farmers out of poverty [3]. The second category of talents is the outbound intellectual support groups, including university students' village officials, experts and scholars in the agricultural field, and technical personnel. These modernized education talents with ample modern knowledge reserves help to promote the reform of the rural economic structure and the overall rural modernization. Strengthening the construction of talent teams in these two areas will enable better utilization of rural resources and enable the "Rural Revitalization" strategy to be implemented more scientifically and effectively.

\subsection{Upgrade the Traditional Rural Industrial Structure}

For the strategy of "rejuvenating villages", Secretary Xi has proposed seven paths and five revitalization plans. Five of them were: the rejuvenation of rural indus- 
tries, the revitalization of talents, the rejuvenation of culture, the revitalization of the economy, and the rejuvenation of organizations, while the rejuvenation of rural industries is the foremost that it is necessary to upgrade and adjust the rural industrial structure [1].

The adjustment of the rural industrial structure is not to abandon or reduce the importance of the original agriculture, but to develop agriculture and introduce other industries in a diversified and modern way. First of all, it is necessary to deepen the structural reform of the agricultural supply side as the main line, accelerate the establishment of a modern agricultural industrial system, a production system, and a management system, and promote the transformation of agriculture from a production-promoting orientation to a quality-oriented one, and continuously improve agricultural innovation. In response to imbalances in the supply and demand of agricultural products and the waste of resources, the government, while strengthening guidance and ensuring effective supply, encouraging agribusiness companies to increase investment in the introduction of talents and technologies, making agricultural products more competitive in the market. Second, we must emphasize industrial diversification. While developing good agriculture, we must also pay attention to the protection of the ecological environment, developing ecological agriculture and tourism agriculture according to local conditions, and stimulate economic growth through the development of tourism. Finally, with modern information technologies such as "Internet Plus", "Big Data", and "Cloud Computing", modernizing traditional agriculture and linking remote rural areas with modern developed cities through networks. It will not only solve the problem of unbalanced supply and demand of agricultural products, but also propagandize rural construction.

\subsection{Strengthen Rural Infrastructure Construction}

As the saying goes, "If you want to be rich, you must first build roads". Weak rural infrastructure is an important obstacle to rural economic development. At present, most of China's rural basic public service facilities are virtually non-existent. Roads, water conservancy, electricity, and medical care are all behind the cities [6]. The hardships of rural living conditions make more young people want to get out of the mountains. The government needs to pay attention to the rural infrastructure, increasing investment in rural production and living infrastructure, accelerating the promotion of urban modernization and public services to rural areas, deepening the integration of urban and rural areas, and improve rural living environment. Farmers will not be energetic and confident to work hard to achieve "village rejuvenation" if their basic needs are not satisfied.

\subsection{Strengthen the Protection of Rural Ecological Environment and Culture}

The realization of the "Village Revitalization" program is not to copy the intact rural areas into a modern city, but to learn from each other's strengths, to introduce modern ideas and technologies to the rural on the basis of maintaining 
rural cultural characteristics, creating a socialist modern new countryside. However, in the rural areas of some developed regions, some high-pollution, high-consumption, low-end industrial enterprises such as waste-to-energy, chemical industries. They stationed in rural areas due to low land prices and low supervision. Not only do they have not played a role in promoting the development of rural economy, but it has destroyed the original rural ecological environment, making the majority of farmers' physical health under threat. To deal with this problem, first of all, grass-roots rural governments should refuse the above-mentioned enterprises to enter rural areas to engage in production activities. Second, they must also strengthen farmers' awareness of the protection of the ecological environment so that they can deeply realize that a good ecological environment in the countryside will not only benefit their own lives. It is also an important factor in promoting rural economic development in the future. In addition, relevant departments need to rescue and repair the ecological environment that has been destroyed [6].

In addition to strengthening the construction of the rural ecological environment, the government should also pay attention to rural culture with local characteristics, learning from the existing ancient towns and ancient villages with rich native characteristics, and use the unique customs, historical background, ecology, and humanities in rural areas to create Villages with original features. It will not only retain excellent traditional Chinese culture, but also integrate with rural tourism, attracting urban consumers to rural tourism, and promote capital flow between urban and rural areas, narrowing the gap.

\subsection{Formulate Preferential Policies to Encourage Enterprises to "Go to the Countryside"}

No matter whether the talent team building, infrastructure construction or cultural construction and ecological environment construction all require sufficient capital investment. It is clear that if it depends solely on the government's fiscal expenditures, it is certainly not enough. This depends on the enterprises' investment in rural areas. The government should formulate a series of preferential policies such as tax cuts and tax exemptions or set up special research and development funds and pay for the promotion of enterprises. All of this will attract and encourage some low-polluting enterprises, especially agricultural enterprises to actively go to rural to product and construct. This will not only ease the financial pressure of the government, but also allow companies to expand the market at a relatively small cost. The economic outlook of the rural areas will also be improved, and a win-win situation for government-enterprise-rural tripartite cooperation will be achieved [7] [8].

\section{Problems Needing Attention in Implementing the "Rural Revitalization" Strategy}

\subsection{Put an End to "Formalism"}

The implementation of the strategy of rural revitalization is a new strategy for 
the development of agriculture, peasants and farmers identified by the Nineteenth Congress. It is different from any new formulation and new slogan. It is a brand-new strategy to promote the transformation and development of agriculture and rural areas and speed up the integration of urban and rural areas by using rural revitalization as a carrier. There must be a new height in the implementation. It is necessary to use a strategic vision to draw up a plan and implement it in a new way of thinking and behavior. To fully implement the strategy of "rejuvenating the countryside", we must first put an end to "formalism". "Village Revitalization" is based on the equality and complementation between urban and rural areas. Then rural areas can be self-realization and prosperity in economy, human settlements, governance, and livelihood of villagers. It is necessary to pragmatically promote the transformation and development of agriculture and rural areas so that rural areas can go to modernization. China has a serious problem of formalism in the era of poverty eradication. It places too much emphasis on the decline in the number of people living in poverty while does not attach importance to the quality of life of the poor. Therefore, when implement the strategy of "rejuvenating villages", the higher authorities must first plan strategic blueprint, step by step, paying attention to both efficiency and quality, and fully convey the core essence of the Party's formulation strategy to subordinate organizations. Second, we must establish supervision and management institutions and set up sound assessment indicators. Government should increase supervision to give severe punishment to individuals and organizations that do not do practical work.

\subsection{Adhere to Regional Balance and Distinctive Development}

To achieve "village rejuvenation", we must stick to the integration of urban and rural development. For a long time, various resources such as capital, land, and talent have flowed into cities from rural areas, leading to the decline of rural areas become more serious. During the process of conducting this strategy, it is necessary to promote the circulation of manpower, material resources and financial resources between urban and rural areas. Neither can we continue to squeeze rural resources, nor can we unilaterally make excessive urban resources flow to the countryside, and actively eliminate all untimely mechanisms, promoting the free flow of urban and rural elements and equal exchanges, and promote the balanced allocation of public resources between urban and rural areas.

The socialism with Chinese characteristics is the general guiding ideology for the implementation of the strategy for the rejuvenation of rural areas [9]. Characteristic development is a basic requirement. "Village Revitalization" is neither a simple copy of rural areas into a developed urban landscape, nor "line production". It should be combined with culture, geography, policies, and economics of different regions, formulating development strategies according to local conditions. 


\section{Summary}

As one of the "seven major strategies" to get into a new era of socialism with Chinese characteristics, the implementation of the strategy not only embodies the idea of "three rural" which is proposed by Xi Jinping, but also fully complies with the longing for the good life of the peasants. The implementation of the strategy of Rural Revitalization requires the cooperation of the government, enterprise and the masses. The government needs to formulate a series of preferential policies, increase financial allocations, co-ordinate and strengthen supervision. The enterprises, especially the agriculture related enterprises should respond to the call actively, providing more employment opportunities for the rural areas. All of us firmly believe and follow the government, devoting our creativity to promote the revitalization of rural areas. We should change the understanding of the relationship between the urban and rural areas in the new stage, grasping the law of rural development, taking the nineteen major reports as the basis, and carry out this important strategic plan with the concerted effort.

\section{References}

[1] Jiang D.B. and Peng C. (2018) Rural Decline in the Process of Urbanization: Causes and Governance: An Analysis of the Implementation Perspective of the "Village Rejuvenation Strategy". Journal of Nanjing Audit University, 15, 16-24.

[2] Fu, C.L. (2018) The New Era Promoting Rural Revitalization with the Integration of Urban and Rural Areas: Objectives, Difficulties, and Paths. Journal of Tonghua Teachers College, 39, 1-8.

[3] Luo, M.X. (2018) Rural Revitalization Needs Better Grassroots Government Services. China County Economics News.

[4] Zhang, Q., Zhang, H.C. and Liu, Z.F. (2018) Rural Revitalization: Strategic Choice from Decline to Revival. Economics and Management, 32, 6-11.

[5] Liu, H.G. (2017) The Key Points of the Strategy of Rural Revitalization and Its Path. China National Conditions and National Power, No. 12, 35-37.

[6] Yang, B.J. (2017) Rural Revitalization: Industry, Infrastructure, Talent and Policy. China Development, 17, 1-4 + 94 + 92-93.

[7] Liu, L.J. (2018) Thinking on the Development of Agriculture-Related Enterprises to Boost the Rejuvenation of the Country. Innovation, 12, 33-41.

[8] Liu, L.J. and Hu, Y.J. (2017) Thoughts on Assisting Rural Enterprises in revitalizing Rural Areas. Journal of the Party School of Hefei Municipal Committee, No. 6, 26-30.

[9] Wang, Y.H. and Su, Y.Q. (2017) Rural Revitalization-A New Strategy for China's Rural Development. Journal of the Central Institute of Socialism, No. 6, 49-55. 